\title{
Hostile takeover: Manipulation of HIF-1 signaling in pathogen-associated cancers (Review)
}

\author{
CAIXIA ZHU $^{1 *}$, QING ZHU $^{1 *}$, CHONG WANG $^{1 *}$, LIMING ZHANG $^{1 *}$, FANG WEI $^{2}$ and QILIANG CAI ${ }^{1}$ \\ ${ }^{1}$ Key Laboratory of Medical Molecular Virology (Ministries of Education and Health), School of Basic Medical Sciences, \\ Fudan University, Shanghai 200032; ${ }^{2}$ Sheng Yushou Center of Cell Biology and Immunology, School of \\ Life Sciences and Biotechnology, Shanghai Jiao Tong University, Shanghai 200240, P.R. China
}

Received April 1, 2016; Accepted May 23, 2016

DOI: $10.3892 /$ ijo.2016.3633

\begin{abstract}
Hypoxia-inducible factor (HIF)-1 is a central regulator in the adaptation process of cell response to hypoxia (low oxygen). Emerging evidence has demonstrated that HIF-1 plays an important role in the development and progression of many types of human diseases, including pathogen-associated cancers. In the present review, we summarize the recent understandings of how human pathogenic agents including viruses, bacteria and parasites deregulate cellular HIF-1 signaling pathway in their associated cancer cells, and highlight the common molecular mechanisms of HIF-1 signaling activated by these pathogenic infection, which could act as potential diagnostic markers and new therapeutic strategies against human infectious cancers.
\end{abstract}

\section{Contents}

1. Introduction

2. HIF-1 activity is directly enhanced by oncogenic viruses at transcriptional or translational level

3. HIF-1 is indirectly activated by bacteria-induced oxidative stress

4. HIF-1 is indirectly upregulated by parasite-mediated iron exhaustion

5. Conclusions

Correspondence to: Dr Fang Wei, ShengYushou Center of Cell Biology and Immunology, School of Life Sciences and Biotechnology, Shanghai Jiao Tong University, Shanghai 200240, P.R. China

E-mail: fangwei@sjtu.edu.cn

Dr Qiliang Cai, Key Laboratory of Medical Molecular Virology (Ministries of Education and Health), School of Basic Medical Sciences, Fudan University, Shanghai 200032, P.R. China

E-mail: qiliang@fudan.edu.cn

${ }^{*}$ Contributed equally

Key words: hypoxia, HIF-1 signaling, infectious cancer

\section{Introduction}

To date approximately one-sixth of global cancers are attributable to an infectious agent (1). The fraction of cancers linked to pathogen infection varies greatly due to geographical location and socioeconomic factors: approximately $8 \%$ in developed countries, up to $23 \%$ in developing countries, and above one-third in Sub-Saharan Africa (1). Carcinogenesis associated with infections is a complex process, often mediated by chronic inflammatory conditions that is a progressive component in the tumor microenvironment and represents a key hallmark of cancer.

Hypoxia (low oxygen) is a phenotype of hostile microenvironment usually formed by cancer cell rapid growth (2). It has been demonstrated that hypoxia occur in many types of human malignancies caused by pathogen infections and tightly associated with chronic inflammation (3). Hypoxia-inducible factor (HIF) is the master regulator molecule in response to hypoxic stress. HIF, that belongs to basic-helix-loop-helix-PAS family, is a heterodimer transcriptional factor composed of an inducible $\alpha$ subunit (HIF $\alpha$, oxygen-dependent) and a constitutively expressed $\beta$ subunit (HIF $\beta$ ) (4). Three HIF isoforms (HIF-1, HIF-2 and HIF-3) have been identified. Since the majority of studies have reported on HIF-1, here we focus on HIF-1 not HIF-2 or HIF-3. The half-life of HIF-1 $\alpha$ protein is very short, and the stability of HIF- $1 \alpha$ will determine its effect. The specific proline residue of HIF-1 $\alpha$ is hydroxylated by prolyl hydroxylases (PHDs) in the presence of oxygen. Upon hydroxylation, HIF-1 $\alpha$ is targeted by the VHL tumor suppressor for ubiquitylation and proteasome-mediated degradation; while in hypoxia condition, the activity of PHD is blocked due to the absence of oxygen, and in turn HIF- $1 \alpha$ is stabilized. The stabilized HIF-1 $\alpha$ translocates into the nucleus and form a heterodimer with HIF-1 $\beta$, where they function as a transcription factor to regulate many downstream genes that are critical for various cellular processes including inflammation and cell survival in hypoxia (5). In addition, substantial evidence has shown that transcription and translation of HIF-1 is regulated by many post-translational modifications including phosphorylation, acetylation and SUMOylation, as well as complex formation with other molecules which are important for HIF-1 accumulation and transactivation under hypoxic conditions (Fig. 1). Generally, the overexpression of HIF-1 in cancers was 


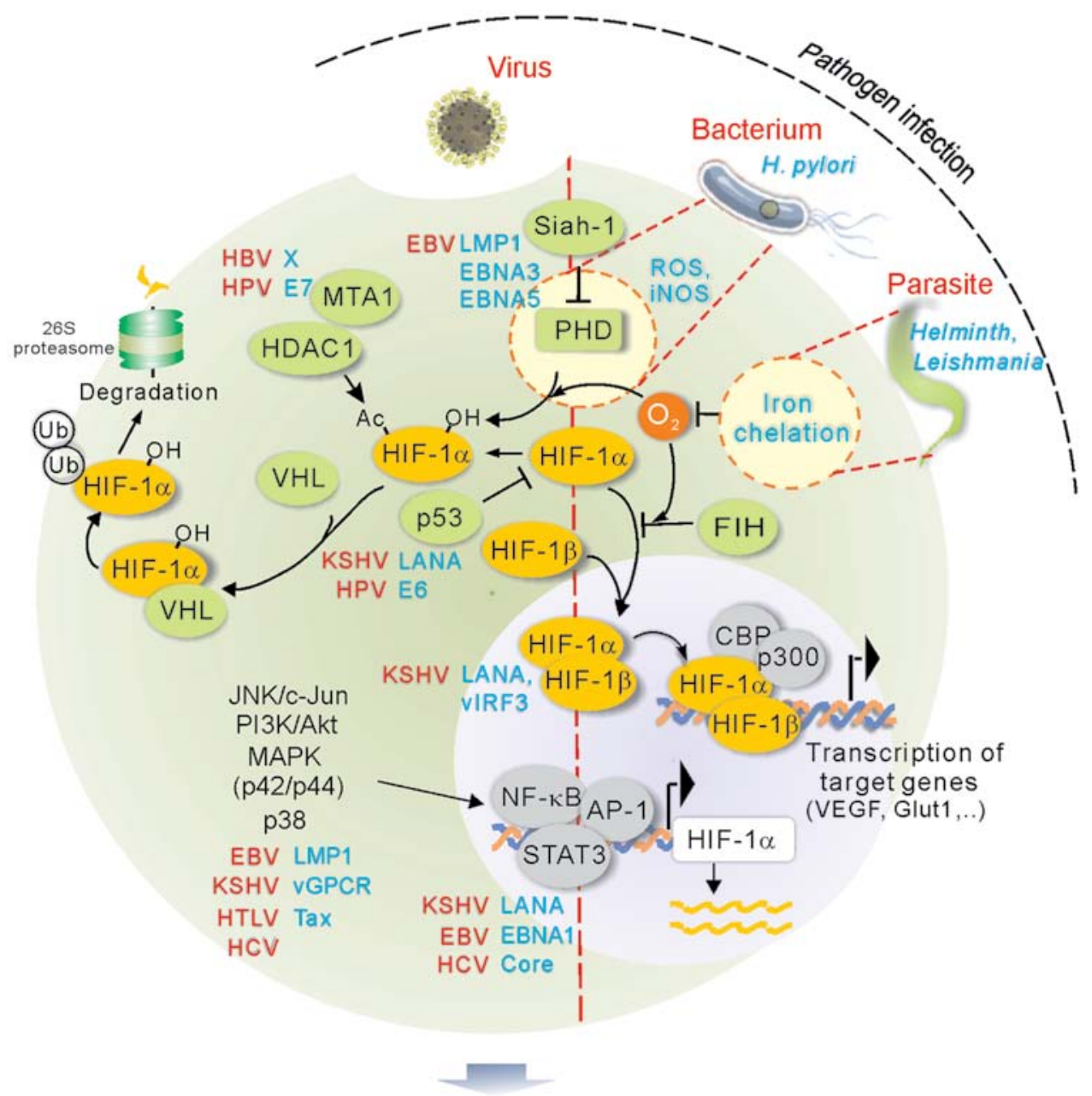

\section{Cell survival \& proliferation}

Figure 1. Overview of HIF-1 signaling pathway hijacked by oncogenic pathogens.

primarily attributed to induction by environmental hypoxia or genetic mutations in the HIF-1-degradation pathways; however, it has now become clear that many human oncogenic pathogens directly enhance HIF-1 stability and activity through various mechanisms. Thus, elevated expression of HIF-1 represents a common outcome of comprehensive regulation by human oncogenic pathogens.

Here we will summarize the current works in understanding the mechanisms of HIF-1 stability and activity promoted by oncogenic pathogens including viruses, bacteria and parasites (Table I), to further address the role of HIF-1 in different oncogenic pathogen-associated cancers, and highlight the potential diagnostic markers and therapeutic targets.

\section{HIF-1 activity is directly enhanced by oncogenic viruses at transcriptional or translational level}

In the past decades, substantial evidence from both epidemiology and experimental study have accumulated pointing out seven different human viruses, namely EBV, HPV, HBV, HTLV, HCV, KSHV and MCV, as causal agents of various human cancers. Inspiringly, six of them, excluding newly discovered MCV, all have been clearly indicated involving in the deregulation of cellular HIF-1 signaling pathway.
$E B V$. Epstein-Barr virus (EBV) is a ubiquitous human $\gamma$-herpesvirus that is associated with lymphoproliferative disease in immunosuppressed patients as well as several types of malignancies, such as Burkitt's lymphoma, lymphoproliferative disorders, T-cell lymphomas, Hodgkin's disease and some gastric carcinomas (6). Previous studies from different research groups successively proposed distinct mechanisms that EBV infection results in accumulation and activation of HIF-1. In particular, the latent-membrane protein 1 (LMP-1), a principal EBV-encoded oncoprotein, has emerged as one of the most important viral proteins associated with HIF-1 $\alpha$. LMP1 expression in the EBV positive cell lines KR-4 and KR-1 was found to lead to increasing expression of HIF-1 $\alpha$, which is through to be activation of $\mathrm{p} 42 / \mathrm{p} 44$ MAPK activity and oxidative stress signaling. LMP1 could promote HIF-1 $\alpha$ DNA binding activity and increase activation of JNK/c-Jun signaling which in turn enhanced HIF-1 $\alpha$ downstream gene (i.e. VEGF) expression (7,8). In addition, LMP1 was also shown to stabilize HIF-1 $\alpha$ in nasopharyngeal epithelial cells through upregulating the level of Siah1 E3 ubiquitin ligase, which induces proteasomal degradation of prolinehydroxylases PHD1 and PHD3 and ultimately inhibits HIF-1 degradation (9). Likewise, EBNA1, as the key antigen during EBV latency, has also been found to enhance transcription 
Table I. Deregulation of pathogens-associated HIF signaling.

\begin{tabular}{|c|c|c|c|c|}
\hline Pathogen & $\begin{array}{l}\text { Associated cancers } \\
\quad(28,61,67,68)\end{array}$ & $\begin{array}{l}\text { Pathogen } \\
\text { molecules }\end{array}$ & $\begin{array}{l}\text { Mechanisms of pathogenic } \\
\text { HIF signaling }\end{array}$ & Refs. \\
\hline \multirow[t]{3}{*}{ EBV } & \multirow[t]{3}{*}{$\begin{array}{l}\text { Burkitt's lymphoma, Hodgkin's B } \\
\text { cell lymphoma, gastric and } \\
\text { nasopharyngeal carcinoma }\end{array}$} & LMP1 & $\begin{array}{l}\text { Degradation of PHD by } \\
\text { Siah1-mediated ubiquitylation; } \\
\text { Phosphorylation of CBP by MAPK (p42/p44); } \\
\text { Activation of JNK/c-Jun } \\
\text { Phosphorylation by ROS signaling }\end{array}$ & $(7-9)$ \\
\hline & & EBNA1 & Enhances transcription of HIF- $1 \alpha$ by targeting AP- 1 & $(10)$ \\
\hline & & $\begin{array}{l}\text { EBNA5, } \\
\text { EBNA3 }\end{array}$ & $\begin{array}{l}\text { Stabilization of HIF-1 } \alpha \text { by blocking interaction with } \\
\text { PHD1 and PHD2 }\end{array}$ & $(11)$ \\
\hline \multirow[t]{3}{*}{ KSHV } & \multirow{3}{*}{$\begin{array}{l}\text { Kaposi's sarcoma, primary } \\
\text { effusion lymphoma, multicentric } \\
\text { Castlman's disease }\end{array}$} & vGPCR & $\begin{array}{l}\text { Activation of MAPK (p42, p44), p38 by } \\
\text { phosphorylation }\end{array}$ & $(41,42)$ \\
\hline & & LANA & $\begin{array}{l}\text { Stabilization and relocation of HIF-1 } \alpha \text {; Degradation } \\
\text { of VHL through EC5S ubiquitin complex }\end{array}$ & $(35,37,38)$ \\
\hline & & vIRF3 & Stabilize HIF-1 $\alpha$ & $(39,40)$ \\
\hline HPV & $\begin{array}{l}\text { Cervix, anus, vulva, penis, } \\
\text { oropharynx }\end{array}$ & $\begin{array}{l}\text { E6 } \\
\text { E7 }\end{array}$ & $\begin{array}{l}\text { NF- } \kappa \text { B activation by inhibiting CYLD deubiquitinase } \\
\text { Enhanced activity of HIF-1 by blocking the } \\
\text { association with HDAC1, HDAC } 4 \text { and HDAC7 }\end{array}$ & $\begin{array}{c}(15) \\
(13,14)\end{array}$ \\
\hline HBV & $\begin{array}{l}\text { Liver cancer } \\
\text { (hepatocellular carcinoma) }\end{array}$ & $\mathrm{X}$ & $\begin{array}{l}\text { Deactylation by MTA1 and HDAC1; Phosphorylation } \\
\text { of CBP by MAPK (p42/p44); }\end{array}$ & $(18,19)$ \\
\hline HLTV & T cell lymphoma & $\operatorname{Tax}$ & Phosphorylation by Akt/PI3K pathway & $(24)$ \\
\hline $\mathrm{HCV}$ & $\begin{array}{l}\text { Liver cancer } \\
\text { (hepatocellular carcinoma) }\end{array}$ & Core & $\begin{array}{l}\text { Likely through phosphorylation of NF-кB, } \\
\text { STAT3, PI3K/Akt, MAPK (p42/p44) }\end{array}$ & $(29,31,32)$ \\
\hline H. pylori & Gastric adenocarcinoma & ND & $\begin{array}{l}\text { Enhanced transcription of HIF-1 by ROS-induced } \\
\text { APE1; Inhibition of HIF-1 by iNOS }\end{array}$ & $(51,54)$ \\
\hline Bartonella & Bacillary angiomatosis (BA) & BadA & ND & $(56,58)$ \\
\hline Helminth & $\begin{array}{l}\text { Bladder carcinoma, } \\
\text { cholangiocarcinoma }\end{array}$ & ND & Induction of a hypoxic microenvironment & $(62)$ \\
\hline Leishmania & Skin cancer & ND & $\begin{array}{l}\text { Exhaustion cellular iron pool; Elevated expression } \\
\text { of HIF-1 by infected macrophage }\end{array}$ & $(66)$ \\
\hline
\end{tabular}

$\mathrm{ND}$, not determined.

of HIF-1 $\alpha$ through modulating the AP-1 transcriptional factor (10). At the post-translational level, more recent studies revealed that $\mathrm{HIF}-1 \alpha$ is also stabilized by EBV-encoded EBNA-5 and EBNA-3 in the EBV-transformed lymphoblastoid cells through binding to PHD1 and PHD2, two of which participate in the degradation of HIF-1 $\alpha$ (11). Interestingly, it has also been shown that hypoxia stress is able to induce EBV lytic replication (12).

$H P V$. HPV, as a typical human oncogenic non-enveloped DNA virus, is characterized by definite causal role in a subset of squamous cell carcinoma, mainly cervical cancer. HPV-encoded E6 and E7 oncoproteins are shown to continuously express in cervical cancer lesions, which reveal the critical role of these two oncoproteins in the development of cervical tumors. Tang and colleagues (13) have demonstrated an increased expression of HIF- $1 \alpha$ and HIF-1 $\alpha$-dependent
VEGF in cervical cancer cells with the overexpression of E6 and E7. Further studies identified that E7 protein enhances HIF-1 activity by blocking the association of HIF-1 with histone deacetylases HDAC1, HDAC4 and HDAC7 (14). Notably, HPV-encoded E6 was found to display a distinct mechanism in regulation of hypoxia signal pathway. For example, E6 protein can prolong hypoxia-induced $\mathrm{NF}-\kappa \mathrm{B}$ activation by inhibiting CYLD lysine 63 deubiquitinase, which is a negative regulator of the $\mathrm{NF}-\kappa \mathrm{B}$ pathway, and then promote HPV-associated malignance (15). These findings shed light on the mechanisms of how HPV contributes to the stabilization and activation of HIF-1.

$H B V$. Hepatitis B virus (HBV), a small DNA virus belongs to hepadnaviridae family, is a globally distributed human pathogen that can cause life-threatening diseases like liver cirrhosis and hepatocellular carcinoma (HCC) (16). The 
HBV-encoded X protein (HBx), as one of the four HBV overlapping open reading frames encoded proteins, were proven with accumulating evidence to play a primary function in angiogenesis during the malignant development of HCC (17). Considering the established role of HIF-1 in angiogenesis, HBx links to HIF-1 has been extensively explored. Among these, a research study from Yoo group depicts a positive association between HBx and the MTA1/HDAC complex in stabilizing HIF-1 $\alpha$. HBx induces expression of both MTA1 and HDAC1 to enhance deacetylation of HIF-1 within oxygen-dependent degradation domain (18). Consistently, Holotnakova et al (19) further found that $\mathrm{HBx}$ could also increase the transcriptional activity of HIF-1, which in turn enhances a hypoxia-responsive gene CA9 promoter activity and contributes to the development of HCC.

HTLV. Among human retrovirus, human T-cell leukemia virus type 1 (HTLV-1), is the only identified retrovirus that directly linked to certain types of human cancer, such as ATL (adult T-cell leukemia). Tax protein has been recognized as one of the most important oncogenic proteins encoded by HTLV-1 (20). Tax has been shown to interact with several transcription factors and involve in activation of several oncogenic pathways, including CREB/ATF, AP1, NF- $\kappa \mathrm{B}$ and the PI3K/Akt signaling pathway (21-23). In hypoxia signaling pathway, Tomita et al (24) showed that phosphorylation of PI3K/Akt induced by Tax leads to activation of HIF-1 in HTLV-infected cell lines, and proposed a PI3K/Akt-dependent mechanism that is responsible for HIF-1 protein accumulation and DNA-binding activity.

$H C V$. Hepatitis C virus (HCV) is a positive-strand RNA virus (25). Since the success of identification of HCV in 1989 by Houghton and colleagues, similar to HBV, the relationship between HCV chronic infection and the development of HCC has been established $(26,27)$. In contrast to the mechanism by which HBV causes HCC, no HCV-derived viral protein has been found to function as oncoprotein. However, chronic inflammation and sustained liver damage caused by HCV infection could likely account for HCV-related hepatocellular carcinoma (28). Also, increasing evidence have shown that a state of oxidative stress is a characteristic manifestation induced by HCV infection (28). Stabilization of HIF-1 $\alpha$ induced by $\mathrm{HCV}$ is potentially attributable to oxidative stress $(29,30)$. For example, Nasimuzzaman et al (29) showed that the activation of NF- $\mathrm{kB}$, STAT-3, PI3K/Akt and p42/44 mitogen-activated protein kinase under oxidative stress strongly link to the HIF-1 $\alpha$ stabilization and VEGF synthesis. In contrast, Ripoli et al (30) provided another explanation that $\mathrm{HCV}$ infection causes severe impairment of mitochondrial oxidative phosphorylation, which results in HIF-1 $\alpha$ stabilization under normoxic condition. Increased HIF-1 $\alpha$ further stimulates the expression of HIF-controlled genes including glycolytic enzymes. More recent studies carried by different research groups disclose that $\mathrm{HCV}$ core protein plays a role in upregulation of HIF-1 $\alpha$ both in transcription and protein level $(31,32)$. However, the related mechanism remains to be further determined. Taken together, all these findings provide new insights into the role of HIF-1 signaling on the carcinogenesis of HCV-related HCC.
$K S H V$. Kaposi's sarcoma-associated herpesvirus (KSHV), as a member of the $\gamma$-herpesviruses, also referred to as human herpesvirus 8 (HHV-8). It is well known that KSHV is tightly associated with Kaposi's sarcoma (KS), primary effusion lymphoma (PEL) and multicentric Castleman's disease (MCD) $(33,34)$. Notably, Kaposi's sarcoma, commonly occurred in untreated AIDS, is an angioproliferative and endothelial cell-derived tumor (35). Given the close link between active HIF-1 and angiogenesis, extensive studies indicate that KSHV has developed multiple distinct mechanisms to regulate HIF-1 signaling in KSHV-infected cells. The latency-associated nuclear antigen (LANA), as a key antigen in KSHV latency state, plays a crucial role not only in KSHV episomal persistence, but also in modulating viral and cellular gene expression $(36,37)$. Research from our group revealed the role of LANA in regulating HIF-1 signaling. LANA is capable of stabilizing HIF- $1 \alpha$ by targeting its suppressor von Hippel-Lindau (VHL) protein and p53 for degradation. This process depends on its suppressor of cytokine signaling (SOCS)-box motif that can recruit the (Elongin BC-Cullin 5-SOCS) EC5S ubiquitin complex (38). In addition, a potential $\alpha$-helical amino-terminal domain of LANA was found responsible for inducing nuclear accumulation of HIF-1 $\alpha$ in normoxic condition (35). In the transcriptional level, LANA is also shown to augment HIF-1 $\alpha$ mRNA level (37). Remarkably, LANA also presents to directly interact with HIF- $1 \alpha$, and binds to the hypoxia-responsive element (HRE) motifs of the viral replication transcription activator (RTA) promoter, which partly explain the mechanism of hypoxia-induced KSHV lytic replication (37).

Although LANA represents a critical role in the deregulation of hypoxia signaling, several other viral proteins encoded by KSHV have also been implicated to associate with HIF-1 $\alpha$. For example, LANA2 (also named vIRF3), which is reported exclusively expressed in KSHV-infected B cells (39), has been shown to stabilize and stimulate HIF-1 $\alpha$ transcriptional activity. LANA2 also interacts with HIF-1 $\alpha$ via a double $\alpha$-helix motif, which could inhibit HIF-1 $\alpha$ degradation under normoxia (40). G protein-coupled receptor (vGPCR), which is encoded by KSHV with the nature of potent transformation and proangiogenesis in KS development (28). Earlier studies have documented the effect of vGPCR in HIF-1 $\alpha$ activity is involved by several intercellular pathways. Sodhi et al (41) elucidated that the phosphorylation of the inhibitory domain of HIF- $1 \alpha$ induced by vGPCR is through the activation of p38 and MAPK signaling pathways, which leads to increased transcriptional activity of HIF-1 $\alpha$ and VEGF protein levels. In addition, it is worth mentioning that cytokines secretion induced by vGPCR also activate several kinase pathways including AKT, p38 and IKK $\beta$, which ultimately stimulate HIF activity and VEGF secretion in a mTOR-independent manner (42). Recently, lytic proteins PF-8 and gpK8.1 and vIL-6 encoded by KSHV are also involved in HIF pathways. In both chronic and acute hypoxia, lytic proteins PF-8 and gpK8.1 are strongly expressed in KSHV-infected primary effusion lymphoma (PEL) cells (43). vIL-6 as an important cytokine in the pathogenesis of $\mathrm{KS}$, is also higher expressed in hypoxia than in normoxia. Collectively, this evidence imply a critical role of HIF-1 $\alpha$ in promoting KSHV latency and lytic replication (43). 
3. HIF-1 is indirectly activated by bacteria-induced oxidative stress

Although it is still debated whether bacterial infection can directly cause human cancer (44), two bacteria Helicobacter pylori (H. pylori) and Bartonella have been widely demonstrated to highly associate with different human cancer development, and their infection can indirectly increase the expression levels of HIF in host cells in innate immune response (45).

H. pylori. Since the success of isolating Helicobacter pylori in 1984, many studies have focused on the casual relationship between the pathogen and peptic ulcer disease as well as gastric cancer (46). H. pylori infection is believed to elevate the risk of gastric cancer development $(47,48)$. Subsequently research work of Griffiths et al has shown an increased expression of hypoxia-inducible protein, like HIF-1 $\alpha$, HIF- $2 \alpha$ and VEGF, in the Barrett's metaplasia-dysplasia-adenocarcinoma sequence (49). Also, they found that the expression of HIF-1 $\alpha$ in gastric cancer development is increasing and is linked to a poor prognosis (48). The evidence together suggest that HIF- $1 \alpha$ is associated with malignant progression of gastric cancer and may play a critical role in carcinogenesis. HIF-1 $\alpha$ has been implicated in proliferation, apoptosis events and the inflammatory process that as a result of $H$. pylori infection, is believed to potentially transform $H$. pylori-induced chronic gastritis into intestinal-type carcinoma. The study of Park et al (50) revealed that HIF-1 $\alpha$ protein is aberrantly expressed in gastric cancer cells under normoxia, and this phenomenon is correlated with endogenous ROS generation. Importantly, they found that $H$. pylori-stimulated gastric epithelial non-mitochondrial ROS can induce HIF-1 $\alpha$ expression as well as activate HIF- $1 \alpha$-mediated transcription. Therefore, they proposed a novel mechanism of stabilization of HIF-1 $\alpha$, which is separate from genetic abnormalities, such as functional loss of VHL tumor suppressor. A recent study from Bhattacharyya et al (51) further explains the underlying mechanism of HIF-1 $\alpha$ stabilization and accumulation in $H$. pylori-infected gastric epithelia under normoxic condition. ROS generation, due to neutrophil infiltration in response to $H$. pylori infection, induces the expression of APE1 in human gastric epithelial cells. Subsequently, APE1 not only augments HIF-1 $\alpha$ expression, but also interacts with transcriptional co-activator p300 enhancing the transcriptional activity of HIF-1 $\alpha$.

In addition to ROS, exogenous reactive nitrogen species has been extensively indicated in gastric carcinogenesis as well as chronic inflammation relevant to gastric cancer (52). A previous study by Mannick et al (53) has shown an increased expression of iNOS and sustained formation of nitric oxide in gastric mucosa in response to $H$. pylori infection. To unravel the molecular mechanism of HIF- $1 \alpha$ accumulation under normoxia by nitric oxide, another group has found that nitric oxide impairs the degradation of HIF-1 $\alpha$ under normoxia by inhibiting S-nitrosoglutathione (GSNO)-mediated prolyl hydroxylases (54). Collectively, the evidence provides us with a novel approach that can be employed by $H$. pylori to regulate the accumulation and activation of HIF-1 $\alpha$ under normoxic condition.
Bartonella. Bartonella species is a gram-negative, fastidious, facultative intracellular bacteria that can infect many different mammalian hosts, and is considered as the only known bacterial pathogen causing vasculoproliferative disorders in humans $(55,56)$. Among of more than 20 species, $B$. henselae and $B$. Quintana are the major causative agents of bacillary angiomatosis (BA) and bacillary peliosis (BP) in immunocompromised patients (57). Kempf et al (56) showed that in BA lesions and B. henselae infected host cells, the expression of HIF-1 is very high, and $B$. henselae infection could result in the activation of cellular genes targeted by hypoxia. Further studies showed that Bartonella adhesin A (BadA) could be crucial for this bacteria to induce angiogenic reprogramming of the host cells via activation of HIF-1 $(56,58)$, however, the related mechanism remains to be further investigated.

\section{HIF-1 is indirectly upregulated by parasite-mediated iron exhaustion}

Although the association of parasite infection with human cancers is not very clear, some evidence has shown that infection of some parasites including Helminth and Leishmania also indirectly impair HIF-1 $\alpha$ signaling in their associated cancers.

Helminth. The prevalence of Helminth infections has a high correlation with geographic region and sanitary condition. Current evidence from epidemiological investigation strongly support the link between a certain type of cancer and a specific parasite (59). Among these, the relationship between bladder cancer and schistosomiasia is relatively explicit, which is mainly based on the observation of superficial transition cell carcinomas in animals infected with $S$. haematobium as well as case-control study (59-61). In addition, the other two trematodes, Opisthorchis viverrini and Clonorchis sinensis, are also believed to be the etiology of cholangiocarcinoma (61). Generally, the development of helminth-related cancer is a chronic process, often require exposure to the infection for many years. Both granulomas formation and inflammatory cell infiltration that responsible for much of the symptom of schistosomiasis, are important inflammation forms in response to $S$. mansoni infection $(62,63)$. Recently, a research group found that Schistosomal granulomas are hypoxic, accompanied by the expression of HIF-1 $\alpha$ and VEGF. The findings for the first time reveal a strong positive correlation between hypoxic tissue microenvironment produced by $S$. mansoni infection and HIF-1 $\alpha$ expression. HIF-1 $\alpha$ expression, in turn, promotes the development and growth of the granulomas (62). Considering the role of chronic inflammation in the development of cancer, hypoxia microenvironment induced HIF-1 $\alpha$ expression is possibly another mechanism employed by a parasite, S. mansoni, to involve in the transformation of helminth-infected tissues.

Leishmania. To date, the links between HIF-1 $\alpha$ and parasites were rarely reported, wherein Leishmania in association with HIF-1 $\alpha$ expand our knowledge on the molecular strategy used by the parasite to deregulate the HIF-1 $\alpha$ signal pathway. Studies from the same group showed that the overexpression of HIF-1 $\alpha$ was found in both Leishmania amazonensis-infected mono- 
nuclear phagocytes and cutaneous lesions of BALB/c mice $(64,65)$. However, the related mechanism of activation needs to be further discovered. Recently, Singh et al (66) showed there are two potential distinct mechanisms in activation of HIF-1 $\alpha$ in Leishmania donovani (LD)-infected macrophages. One is that LD can exhaust host cellular iron pool and then affect prolyl hydroxylase activity, which contributes to the stabilization of HIF-1 $\alpha$ protein. On the other hand, an elevated expression of HIF-1 $\alpha$ may due to the transcriptional regulation in the LD-infected macrophage.

\section{Conclusions}

Distinct from other non-pathogen associated cancers, elucidation of the molecular events underlying the carcinogenesis of human tumors associated with pathogen will facilitate to develop a specific pathogen-targeted therapeutic strategy. In the view of the fact that HIF-1 acts as a central regulator in the adaptation process of cells and organisms to hypoxia, and plays an important role in human pathogen-associated inflammatory cancers, it is possible to prevent pathogenic infection by using HIF-1-specific inhibitors. Hence, we highlight the molecular mechanisms of HIF-1 and HIF-1-dependent downstream target gene activation directly controlled by pathogenic infections, while exploring the effect of hypoxic stress on pathogenic life cycle and chromosome instability in infected host cells. In the present review, we enumerate at least six oncogenic viruses that have clearly been implicated in the modulation of HIF-1 signaling. Compared to other viruses, KSHV and EBV, two members of $\gamma$-herpesvirus family, develop multiple mechanisms and encode more than one viral protein to shape the HIF-1 activity in hypoxic, even normoxic condition. For example, KSHV LANA, vIRF-3 and vGPCR adopt a unique method, respectively, which ultimately leads to increased HIF-1 activity, including enhanced HIF-1 protein level and transcription activity. From this view, more strategies and resources from virus itself reflect the important role of HIF-1 signaling in the development of virus associated tumors. With regard to bacteria and parasites, no direct link between HIF-1 and bacteria or parasite derived molecular mechanisms was reported. The regulation of HIF-1 by bacteria or parasite is mainly attributable to indirect effect of infection, like iNOS and ROS induced by $H$. pylori. Thus, it remains to be further investigated. Collectively, understanding the role of HIF-1 in the progression of different oncogenic pathogen-associated cancers, and the mechanisms by which oncogenic pathogens including viruses, bacteria and parasites promote HIF-1 stability and activity, will provide us with more diagnostic markers and potential viral targets for therapeutic application.

\section{Acknowledgements}

The authors would like to apologize to the many researchers who have contributed to this area of research but have not been cited in this review due to space limitations. The present study is supported by the Research and Innovation Program of the Shanghai Municipal Education (13zz011), the Shanghai Sailing Program (15YF1400900), the National Natural Science Foundation of China $(81471930,81402542,81501739)$, and the National Key Basic Research '973' program of China
(2012CB519001). F.W. is a scholar of Pujiang Talents in Shanghai. Q.C. is a scholar of New Century Excellent Talents in University of China.

\section{References}

1. de Martel C, Ferlay J, Franceschi S, Vignat J, Bray F, Forman D and Plummer M: Global burden of cancers attributable to infections in 2008: A review and synthetic analysis. Lancet Oncol 13: 607-615, 2012.

2. Ackerman D and Simon MC: Hypoxia, lipids, and cancer: Surviving the harsh tumor microenvironment. Trends Cell Biol 24: 472-478, 2014.

3. Carmeliet P and Jain RK: Principles and mechanisms of vessel normalization for cancer and other angiogenic diseases. Nat Rev Drug Discov 10: 417-427, 2011.

4. Minet E, Michel G, Remacle J and Michiels C: Role of HIF-1 as a transcription factor involved in embryonic development, cancer progression and apoptosis (Review). Int J Mol Med 5: 253-259, 2000.

5. Kurihara T, Westenskow PD and Friedlander M: Hypoxiainducible factor (HIF)/vascular endothelial growth factor (VEGF) signaling in the retina. Adv Exp Med Biol 801: 275-281, 2014.

6. Calderwood MA, Venkatesan K, Xing L, Chase MR, Vazquez A, Holthaus AM, Ewence AE, Li N, Hirozane-Kishikawa T, Hill DE, et al: Epstein-Barr virus and virus human protein interaction maps. Proc Natl Acad Sci USA 104: 7606-7611, 2007.

7. Wakisaka N, Kondo S, Yoshizaki T, Murono S, Furukawa M and Pagano JS: Epstein-Barr virus latent membrane protein 1 induces synthesis of hypoxia-inducible factor 1 alpha. Mol Cell Biol 24: 5223-5234, 2004

8. Yang L, Liu L, Xu Z, Liao W, Feng D, Dong X, Xu S, Xiao L, Lu J, Luo X, et al: EBV-LMP1 targeted DNAzyme enhances radiosensitivity by inhibiting tumor angiogenesis via the JNKs/ HIF-1 pathway in nasopharyngeal carcinoma. Oncotarget 6: 5804-5817, 2015.

9. Kondo S, Seo SY, Yoshizaki T, Wakisaka N, Furukawa M, Joab I, Jang KL and Pagano JS: EBV latent membrane protein 1 up-regulates hypoxia-inducible factor lalpha through Siah1mediated down-regulation of prolyl hydroxylases 1 and 3 in nasopharyngeal epithelial cells. Cancer Res 66: 9870-9877, 2006.

10. O'Neil JD, Owen TJ, Wood VH, Date KL, Valentine R, Chukwuma MB, Arrand JR, Dawson CW and Young LS: Epstein-Barr virus-encoded EBNA1 modulates the AP-1 transcription factor pathway in nasopharyngeal carcinoma cells and enhances angiogenesis in vitro. J Gen Virol 89: 2833-2842, 2008.

11. Darekar S, Georgiou K, Yurchenko M, Yenamandra SP, Chachami G, Simos G, Klein G and Kashuba E: Epstein-Barr virus immortalization of human B-cells leads to stabilization of hypoxia-induced factor 1 alpha, congruent with the Warburg effect. PLoS One 7: e42072, 2012.

12. Jiang JH, Wang N, Li A, Liao WT, Pan ZG, Mai SJ, Li DJ, Zeng MS, Wen JM and Zeng YX: Hypoxia can contribute to the induction of the Epstein-Barr virus (EBV) lytic cycle. J Clin Virol 37: 98-103, 2006.

13. Tang X, Zhang Q, Nishitani J, Brown J, Shi S and Le AD: Overexpression of human papillomavirus type 16 oncoproteins enhances hypoxia-inducible factor 1 alpha protein accumulation and vascular endothelial growth factor expression in human cervical carcinoma cells. Clin Cancer Res 13: 2568-2576, 2007.

14. Bodily JM, Mehta KP and Laimins LA: Human papillomavirus E7 enhances hypoxia-inducible factor 1-mediated transcription by inhibiting binding of histone deacetylases. Cancer Res 71: 1187-1195, 2011.

15. An J, Mo D, Liu H, Veena MS, Srivatsan ES, Massoumi R and Rettig MB: Inactivation of the CYLD deubiquitinase by HPV E6 mediates hypoxia-induced NF-kappaB activation. Cancer Cell 14: 394-407, 2008

16. Roman S, Jose-Abrego A, Fierro NA, Escobedo-Melendez G, Ojeda-Granados C, Martinez-Lopez E and Panduro A: Hepatitis B virus infection in Latin America: A genomic medicine approach. World J Gastroenterol 20: 7181-7196, 2014.

17. Ali A, Abdel-Hafiz H, Suhail M, Al-Mars A, Zakaria MK, Fatima K, Ahmad S, Azhar E, Chaudhary A and Qadri I: Hepatitis B virus, HBx mutants and their role in hepatocellular carcinoma. World J Gastroenterol 20: 10238-10248, 2014. 
18. Yoo YG, Na TY, Seo HW, Seong JK, Park CK, Shin YK and Lee MO: Hepatitis B virus X protein induces the expression of MTA1 and HDAC1, which enhances hypoxia signaling in hepatocellular carcinoma cells. Oncogene 27: 3405-3413, 2008

19. Holotnakova T, Tylkova L, Takacova M, Kopacek J, Petrik J, Pastorekova S and Pastorek J: Role of the HBx oncoprotein in carbonic anhydrase 9 induction. J Med Virol 82: 32-40, 2010

20. Matsuoka M and Jeang KT: Human T-cell leukaemia virus type 1 (HTLV-1) infectivity and cellular transformation. Nat Rev Cancer 7: 270-280, 2007.

21. Grassmann R, Aboud M and Jeang KT: Molecular mechanisms of cellular transformation by HTLV-1 Tax. Oncogene 24: 5976-5985, 2005.

22. Jeong SJ, Dasgupta A, Jung KJ, Um JH, Burke A, Park HU and Brady JN: PI3K/AKT inhibition induces caspase-dependent apoptosis in HTLV-1-transformed cells. Virology 370: 264-272, 2008.

23. Peloponese JM Jr and Jeang KT: Role for Akt/protein kinase B and activator protein-1 in cellular proliferation induced by the human T-cell leukemia virus type 1 tax oncoprotein. J Biol Chem 281: 8927-8938, 2006.

24. Tomita M, Semenza GL, Michiels C, Matsuda T, Uchihara JN Okudaira T, Tanaka Y, Taira N, Ohshiro K and Mori N: Activation of hypoxia-inducible factor 1 in human T-cell leukaemia virus type 1-infected cell lines and primary adult T-cell leukaemia cells. Biochem J 406: 317-323, 2007.

25. Appel N, Schaller T, Penin F and Bartenschlager R: From structure to function: New insights into hepatitis C virus RNA replication. J Biol Chem 281: 9833-9836, 2006.

26. Tan A, Yeh SH, Liu CJ, Cheung C and Chen PJ: Viral hepatocarcinogenesis: From infection to cancer. Liver Int 28: 175-188, 2008

27. Bergonzini V, Salata C, Calistri A, Parolin C and Palù G: View and review on viral oncology research. Infect Agent Cancer 5: 11, 2010.

28. Martin D and Gutkind JS: Human tumor-associated viruses and new insights into the molecular mechanisms of cancer. Oncogene 27 (Suppl 2): S31-S42, 2008.

29. Nasimuzzaman M, Waris G, Mikolon D, Stupack DG and Siddiqui A: Hepatitis $\mathrm{C}$ virus stabilizes hypoxia-inducible factor 1 alpha and stimulates the synthesis of vascular endothelial growth factor. J Virol 81: 10249-10257, 2007.

30. Ripoli M, D'Aprile A, Quarato G, Sarasin-Filipowicz M, Gouttenoire J, Scrima R, Cela O, Boffoli D, Heim MH, Moradpour D, et al: Hepatitis C virus-linked mitochondrial dysfunction promotes hypoxia-inducible factor 1 alpha-mediated glycolytic adaptation. J Virol 84: 647-660, 2010

31. Liu XH, Zhou X, Zhu CL, Song H and Liu F: Effects of HCV core protein on the expression of hypoxia-inducible factor 1 alpha and vascular endothelial growth factor. Zhonghua Gan Zang Bing Za Zhi 19: 751-754, 2011 (In Chinese).

32. Abe M, Koga H, Yoshida T, Masuda H, Iwamoto H, Sakata M, Hanada S, Nakamura T, Taniguchi E, Kawaguchi T, et al: Hepatitis $\mathrm{C}$ virus core protein upregulates the expression of vascular endothelial growth factor via the nuclear factor- $\kappa \mathrm{B} /$ hypoxia-inducible factor- $1 \alpha$ axis under hypoxic conditions. Hepatol Res 42: 591-600, 2012

33. Mesri EA, Cesarman E and Boshoff C: Kaposi's sarcoma and its associated herpesvirus. Nat Rev Cancer 10: 707-719, 2010.

34. Cesarman E, Chang Y, Moore PS, Said JW and Knowles DM: Kaposi's sarcoma-associated herpesvirus-like DNA sequences in AIDS-related body-cavity-based lymphomas. N Engl J Med 332: 1186-1191, 1995.

35. Cai Q, Murakami M, Si H and Robertson ES: A potential alphahelix motif in the amino terminus of LANA encoded by Kaposi's sarcoma-associated herpesvirus is critical for nuclear accumulation of HIF-1alpha in normoxia. J Virol 81: 10413-10423, 2007.

36. Cotter MA II and Robertson ES: The latency-associated nuclear antigen tethers the Kaposi's sarcoma-associated herpesvirus genome to host chromosomes in body cavity-based lymphoma cells. Virology 264: 254-264, 1999.

37. Cai Q, Lan K, Verma SC, Si H, Lin D and Robertson ES Kaposi's sarcoma-associated herpesvirus latent protein LANA interacts with HIF-1 alpha to upregulate RTA expression during hypoxia: Latency control under low oxygen conditions. J Virol 80: 7965-7975, 2006

38. Cai QL, Knight JS, Verma SC, Zald P and Robertson ES: EC5S ubiquitin complex is recruited by KSHV latent antigen LANA for degradation of the VHL and p53 tumor suppressors. PLoS Pathog 2: e116, 2006.
39. Rivas C, Thlick AE, Parravicini C, Moore PS and Chang Y: Kaposi's sarcoma-associated herpesvirus LANA2 is a B-cellspecific latent viral protein that inhibits p53. J Virol 75: 429-438, 2001.

40. Shin YC, Joo CH, Gack MU, Lee HR and Jung JU: Kaposi's sarcoma-associated herpesvirus viral IFN regulatory factor 3 stabilizes hypoxia-inducible factor-1 alpha to induce vascular endothelial growth factor expression. Cancer Res 68: 1751-1759, 2008.

41. Sodhi A, Montaner S, Patel V, Zohar M, Bais C, Mesri EA and Gutkind JS: The Kaposi's sarcoma-associated herpes virus $G$ protein-coupled receptor up-regulates vascular endothelial growth factor expression and secretion through mitogen-activated protein kinase and p38 pathways acting on hypoxia-inducible factor 1alpha. Cancer Res 60: 4873-4880, 2000.

42. Jham BC, Ma T, Hu J, Chaisuparat R, Friedman ER, Pandolfi PP, Schneider A, Sodhi A and Montaner S: Amplification of the angiogenic signal through the activation of the TSC/mTOR/HIF axis by the KSHV vGPCR in Kaposi's sarcoma. PLoS One 6: e19103, 2011.

43. Davis DA, Rinderknecht AS, Zoeteweij JP, Aoki Y, ReadConnole EL, Tosato G, Blauvelt A and Yarchoan R: Hypoxia induces lytic replication of Kaposi sarcoma-associated herpesvirus. Blood 97: 3244-3250, 2001.

44. Samaras V, Rafailidis PI, Mourtzoukou EG, Peppas G and Falagas ME: Chronic bacterial and parasitic infections and cancer: A review. J Infect Dev Ctries 4: 267-281, 2010.

45. Nizet V and Johnson RS: Interdependence of hypoxic and innate immune responses. Nat Rev Immunol 9: 609-617, 2009.

46. Dorer MS, Talarico S and Salama NR: Helicobacter pylori's unconventional role in health and disease. PLoS Pathog 5: e1000544, 2009.

47. Nardone G, Rocco A and Malfertheiner P: Review article: Helicobacter pylori and molecular events in precancerous gastric lesions. Aliment Pharmacol Ther 20: 261-270, 2004.

48. Griffiths EA, Pritchard SA, Valentine HR, Whitchelo N, Bishop PW, Ebert MP, Price PM, Welch IM and West CM: Hypoxia-inducible factor-1alpha expression in the gastric carcinogenesis sequence and its prognostic role in gastric and gastro-oesophageal adenocarcinomas. Br J Cancer 96: 95-103, 2007.

49. Griffiths EA, Pritchard SA, McGrath SM, Valentine HR, Price PM, Welch IM and West CM: Increasing expression of hypoxia-inducible proteins in the Barrett's metaplasia-dysplasiaadenocarcinoma sequence. Br J Cancer 96: 1377-1383, 2007.

50. Park JH, Kim TY, Jong HS, Kim TY, Chun YS, Park JW, Lee CT, Jung HC, Kim NK and Bang YJ: Gastric epithelial reactive oxygen species prevent normoxic degradation of hypoxiainducible factor-1alpha in gastric cancer cells. Clin Cancer Res 9: 433-440, 2003.

51. Bhattacharyya A, Chattopadhyay R, Hall EH, Mebrahtu ST, Ernst PB and Crowe SE: Mechanism of hypoxia-inducible factor 1 alpha-mediated Mcl1 regulation in Helicobacter pyloriinfected human gastric epithelium. Am J Physiol Gastrointest Liver Physiol 299: G1177-G1186, 2010.

52. Ohshima $\mathrm{H}$ and Bartsch $\mathrm{H}$ : Chronic infections and inflammatory processes as cancer risk factors: Possible role of nitric oxide in carcinogenesis. Mutat Res 305: 253-264, 1994.

53. Mannick EE, Bravo LE, Zarama G, Realpe JL, Zhang XJ, Ruiz B, Fontham ET, Mera R, Miller MJ and Correa P: Inducible nitric oxide synthase, nitrotyrosine, and apoptosis in Helicobacter pylori gastritis: Effect of antibiotics and antioxidants. Cancer Res 56: 3238-3243, 1996.

54. Metzen E, Zhou J, Jelkmann W, Fandrey J and Brüne B: Nitric oxide impairs normoxic degradation of HIF-1alpha by inhibition of prolyl hydroxylases. Mol Biol Cell 14: 3470-3481, 2003.

55. Yuan C, Zhu C, Wu Y, Pan X and Hua X: Bacteriological and molecular identification of Bartonella species in cats from different regions of China. PLoS Negl Trop Dis 5: e1301, 2011.

56. Kempf VA, Lebiedziejewski M, Alitalo K, Wälzlein JH, Ehehalt U, Fiebig J, Huber S, Schütt B, Sander CA, Müller S, et al: Activation of hypoxia-inducible factor-1 in bacillary angiomatosis: Evidence for a role of hypoxia-inducible factor-1 in bacterial infections. Circulation 111: 1054-1062, 2005.

57. Relman DA, Falkow S, LeBoit PE, Perkocha LA, Min KW, Welch DF and Slater LN: The organism causing bacillary angiomatosis, peliosis hepatis, and fever and bacteremia in immunocompromised patients. N Engl J Med 324: 1514, 1991. 
58. Kaiser PO, Riess T, Wagner CL, Linke D, Lupas AN, Schwarz H, Raddatz G, Schäfer A and Kempf VA: The head of Bartonella adhesin A is crucial for host cell interaction of Bartonella henselae. Cell Microbiol 10: 2223-2234, 2008.

59. Porta C, Riboldi E and Sica A: Mechanisms linking pathogensassociated inflammation and cancer. Cancer Lett 305: 250-262, 2011.

60. Mostafa MH, Sheweita SA and O'Connor PJ: Relationship between schistosomiasis and bladder cancer. Clin Microbiol Rev 12: 97-111, 1999

61. Vennervald BJ and Polman K: Helminths and malignancy. Parasite Immunol 31: 686-696, 2009.

62. Araújo AP, Frezza TF, Allegretti SM and Giorgio S: Hypoxia, hypoxia-inducible factor-1 $\alpha$ and vascular endothelial growth factor in a murine model of Schistosoma mansoni infection. Exp Mol Pathol 89: 327-333, 2010.

63. Wilson MS, Mentink-Kane MM, Pesce JT, Ramalingam TR, Thompson R and Wynn TA: Immunopathology of schistosomiasis. Immunol Cell Biol 85: 148-154, 2007.
64. Arrais-Silva WW, Paffaro VA Jr, Yamada AT and Giorgio S: Expression of hypoxia-inducible factor-1alpha in the cutaneous lesions of $\mathrm{BALB} / \mathrm{c}$ mice infected with Leishmania amazonensis. Exp Mol Pathol 78: 49-54, 2005.

65. Degrossoli A, Bosetto MC, Lima CB and Giorgio S: Expression of hypoxia-inducible factor 1alpha in mononuclear phagocytes infected with Leishmania amazonensis. Immunol Lett 114: 119-125, 2007.

66. Singh AK, Mukhopadhyay C, Biswas S, Singh VK and Mukhopadhyay CK: Intracellular pathogen Leishmania donovani activates hypoxia inducible factor-1 by dual mechanism for survival advantage within macrophage. PLoS One 7: e38489, 2012.

67. Morsy TA: Cutaneous leishmaniasis predisposing to human skin cancer: Forty years local and regional studies. J Egypt Soc Parasitol 43: 629-648, 2013

68. Suzuki H, Iwasaki E and Hibi T: Helicobacter pylori and gastric cancer. Gastric Cancer 12: 79-87, 2009. 